\title{
Timing the Early Events during Sea Urchin Fertilization
}

\author{
Gerald SchatTEn AND Dieter HÜLSER ${ }^{1}$ \\ Department of Biological Science, Florida State University, Tallahassee, Florida $\$ 2306$ \\ Received February 1, 1983; accepted in revised form May 16, 1983
}

\begin{abstract}
To determine precisely the timing, duration, and sequences of the earliest events during sea urchin (Lytechinus variegatus) fertilization, the bioelectric recordings of microelectrode-impaled eggs were electronically superimposed, by video mixing, over the microscopic differential interference contrast image of the same egg at insemination. Videotape analysis, utilizing a slow-motion analyzer, demonstrates that the successful sperm triggers the bioelectric membrane potential reversal within $3.36 \pm 3.02$ sec $(0.72-9.76$ sec range; $\Sigma=23$ eggs) of sperm-egg attachment. This sperm, actively gyrating about its attachment site, is indistinguishable from the other, unsuccessful sperm until $12.66 \pm 2.72$ sec (6.72-16.60 sec range; $\Sigma=15)$ later when the sperm tail ceases its beating and sperm incorporation ensues. The cortical granules begin to discharge, and the fertilization coat starts to elevate at the fusion site at $20.79 \pm 3.18 \mathrm{sec}$ (13.62-26.08 sec range; $\Sigma=12$ ) after the onset of the fertilization potential, i.e., an average of about 8 sec after the cessation of sperm-tail motility during incorporation. In most cases, the bioelectric responses starts within $7 \mathrm{sec}$ of sperm adhesions; if the data are analyzed excluding the few slow cases, the fertilization potential is found to start $1.93 \mathrm{sec}( \pm 1.28 \mathrm{sec})$ after sperm attachment. These results indicate that the first successful sperm triggers the fast block to polyspermy within $3.4 \mathrm{sec}$, perhaps as quickly as 1.9 sec, of sperm-egg adhesion, about 13 sec before the first morphological indication of fertilization, and about $21 \mathrm{sec}$ before the characteristic elevation of the fertilization coat responsible for the late block to polyspermy.
\end{abstract}

\section{INTRODUCTION}

Within seconds of sperm-egg attachment, a number of events occur during fertilization, including the onset of membrane potential (Steinhardt et al., 1971; Jaffe, 1976; Chambers and de Armendi, 1979; reviewed by Hagiwara and Jaffe, 1979), resistance and capacitance changes (Jaffe et al., 1978; Dale et al., 1978; De Felice and Dale, 1979), sperm incorporation characterized by both egg-mediated formation of the fertilization cone and the cessation of sperm-tail beating (reviewed by Schatten, 1982), and extracellular modifications (reviewed by Shapiro and Eddy, 1980) including the fertilization envelope elevation resulting from the secretion of the cortical granules (Endo, 1960). The sequence and timing of events during sea urchin fertilization has been investigated by numerous biophysical and microscopic techniques. These include membrane capacitance studies as a measure of cortical granule fusion (Jaffe et al., 1978; Dale et al., 1978) and microscopic data including differential interference video recordings (Schatten, 1981), scanning electron microscopy (Schatten and Schatten, 1980; Schatten and Mazia, 1976), transmission electron microscopy (Endo, 1960; Longo and Anderson, 1968), and immunofluorescence and immunoelectron microscopy using nonspecific antibodies directed against a protein secreted during the cortical reaction, e.g., hyalin ( $\mathrm{Hy}-$

\footnotetext{
${ }^{1}$ Permanent address: Biologisches Institut, Universität Stuttgart, Ulmer Str. 227, D7000 Stuttgart 60, W. Germany.
}

lander and Summers, 1982; McClay and Fink, 1982), and cytoskeletal components, e.g., tubulin (Bestor and Schatten, 1981; Harris et al., 1980). In this report, the timing of the bioelectric and microscopic events during sea urchin fertilization was investigated by video signal mixing and videotape replay analysis.

\section{MATERIALS AND METHODS}

To determine the timing of the early events during fertilization, the video signals of the bioelectric responses of single eggs during fertilization were electronically superimposed on the video differential interference contrast microscopic images obtained from the same eggs (Fig. 1). The microscopic analysis was performed using a Zeiss Universal microscope equipped with differential interference and phase-contrast optics and mounted on air-supported vibration dampers (Schatten, 1981). A water immersion $40 \times$ objective was used routinely and was electrically insulated from the bathing medium with violin rosin. The microscopic image was recorded with a 1-in. Newvicon camera equipped with a $4 \times$ electronic magnification display (Dage-MTI MK11-65). A time-date generator (Panasonic WJ810) with a stop clock display in 10 -msec intervals ensured accurate timing. Electrophysiological recordings and gametes of Lytechinus variegatus at $23^{\circ} \mathrm{C}$ were obtained as described by Hülser and Schatten (1982). Electrode resistances ranged from 50 to $95 \mathrm{M} \Omega$ (mean: $74.25 \pm 20.21$ 


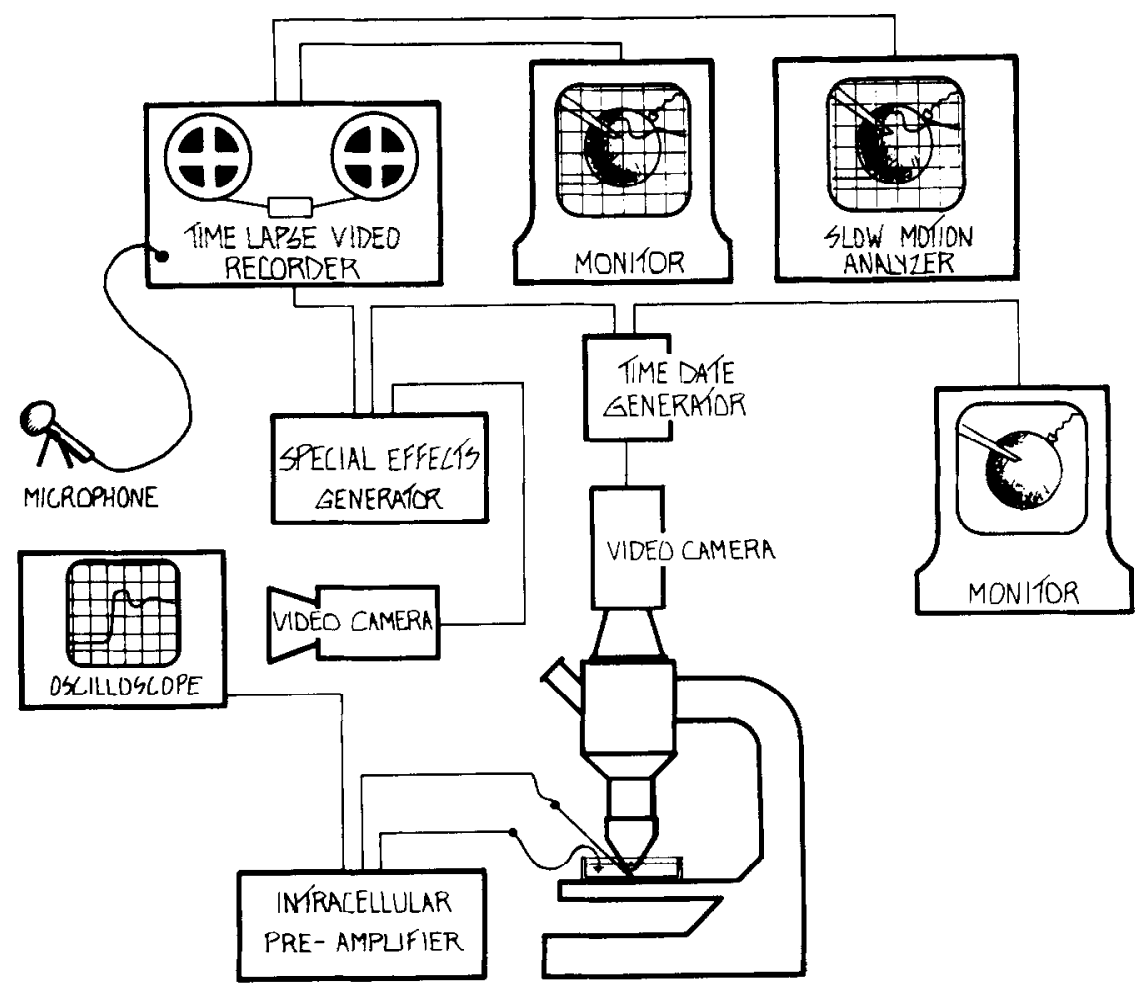

FIG. 1. Timing the bioelectric and microscopic events during fertilization. Video images of the oscilloscope tracing, the differential interference contrast image of a microelectrode-impaled egg at fertilization, and a stop watch display $(10 \mathrm{msec})$ were electronically superimposed. Videotapes were analyzed with a slow-motion analyzer to determine the time required for sperm adhesion, the onset of the bioelectric events, sperm incorporation, and the initiation of the cortical reaction (see text for details).

$\mathrm{M} \Omega$ ). The membrane resistance of the impaled unfertilized eggs ranged from 41 to $160 \mathrm{M} \Omega$ (mean: 79.44 $\pm 34.24 \mathrm{M} \Omega$ ). The oscilloscope screen was recorded with another Newvicon video camera (Panasonic WV1350), the sweep of which was synchronized with the master camera (Colorado Video synch stripper 302-2). A specialeffects generator (Colorado Video 603A) mixed the video signals from the microscope, the microelectrode recordings, and the time-date generator. This signal was recorded on either $1 / 2$ or $3 / 4$ in. videotape with real time or time-lapse video recorders (Sony TV0-9000 or Panasonic NV8030), respectively. Analysis of the videotapes was performed with a slow-motion videotape analyzer (Sony SVM-1010) capable of single-field advance and reverse. Extremely low sperm concentrations were used for insemination; typically fewer than six sperm adhered to the studied egg by a minute after insemination. Sperm adhesion, a rapid event, was characterized by the attachment of the sperm head to the egg surface. The degrees of monospermy and polyspermy were determined in the impaled egg by counting of the number of fertilization cones, protruding sperm tails during incorporation, sperm asters, and number of cleavage furrows; in the adjacent eggs, the extent of fertilization and polyspermy rate were determined by counting the percentage of eggs that divided after $60 \mathrm{~min}$.

\section{RESULTS}

The results of this study, presented in Table 1, demonstrate that, during monospermic inseminations, the fertilization potential starts within $3.36( \pm 3.03)$ sec of sperm-egg adhesion. If the few eggs that required $>7$ sec for the onset of the bioelectric responses are excluded from the calculations, the fertilization potential is found to start at 1.93 seconds $( \pm 1.28 \mathrm{sec})$ following sperm adhesion. During the subsequent seconds, the successful sperm is indistinguishable from the others, and it is only by replay and reversal of the videotape that the fertilizing sperm may be determined. At $12.66( \pm 2.72)$ sec after the onset of the bioelectric responses the first morphological event of fertilization is observed, i.e., the cessation of sperm-tail beating as sperm incorporation begins. At $20.79( \pm 3.17)$ sec after the start of the electrical changes, the discharge of the cortical granules adjacent to the site of sperm-egg fusion is noted. In our studies $43 \%$ of all the unfertilized eggs were electrically excitable when stimulated through the recording electrode as noted in this species by Chambers and De Armendi (1979). Unsuccessful sperm are separated from 
TABLE 1

Timing of Early Events during Fertilization

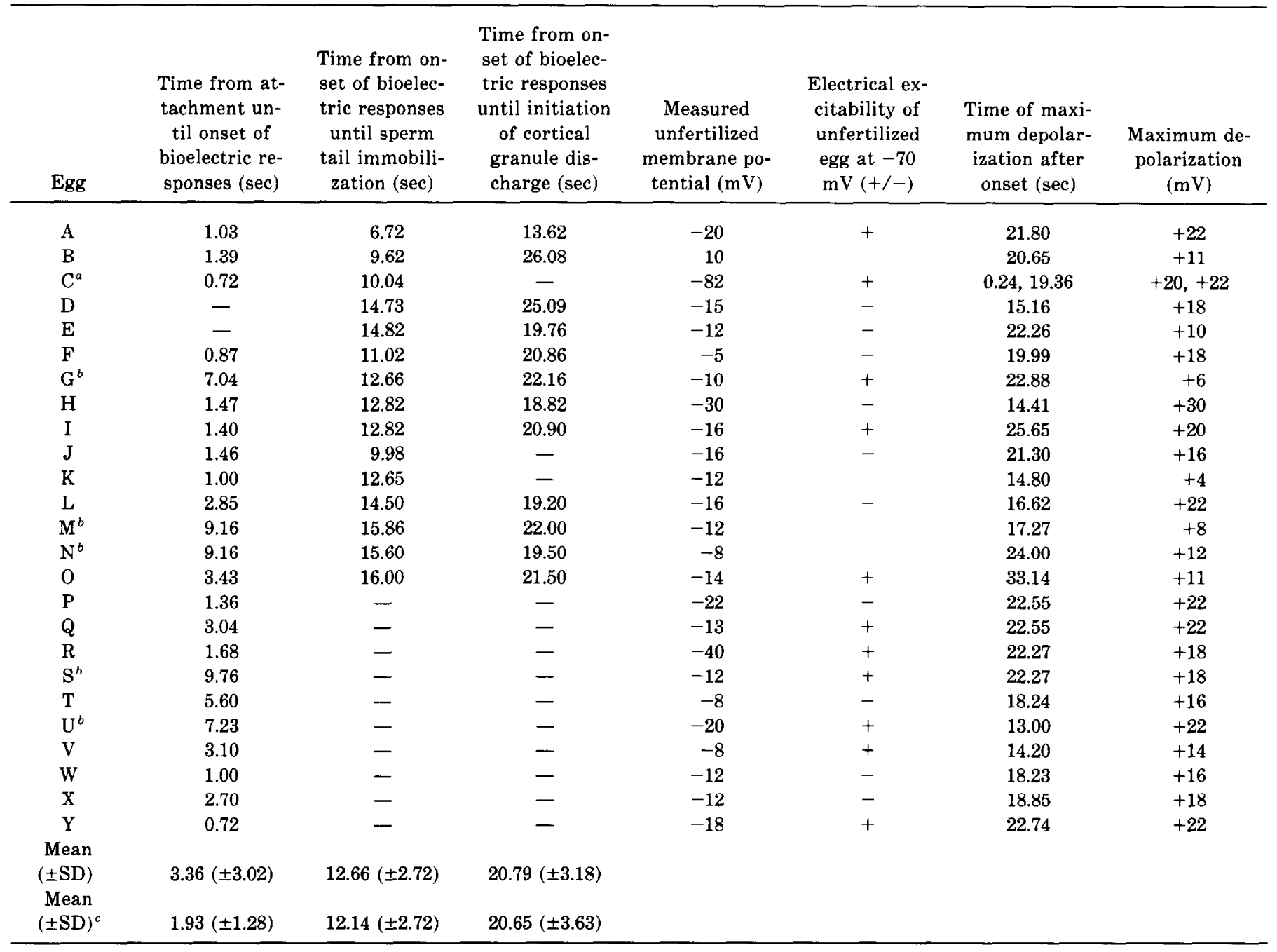

a This excitable egg displayed a sudden rapid electrical membrane potential reversal followed by a slower, longer lasting one.

${ }^{b}$ Denotes excluded data.

${ }^{c}$ Mean $\pm \mathrm{SD}$ of eggs undergoing onset of fertilization potential within $7 \mathrm{sec}$ of sperm incorporation.

the egg plasma membrane by the elevation of the fertilization envelope; they continue to gyrate about their attachment sites until they detach and swim out of the microscopic field.

\section{DISCUSSION}

Though 344 eggs of the sea urchin Lytechinus variegatus were studied for their electrical and morphological responses at fertilization, only about 25 were suitable for the analysis presented in Table 1. Sperm frequently entered the studied eggs at a focal plane other than the upper surface of the egg or at a region of the egg excluded from the video field, and polyspermy was observed at a greater frequency in these microelectrode-impaled eggs. This latter point is of some in- terest in consideration of the controversy surrounding the existence of the fast block to polyspermy and the true, as opposed to measured, resting potential of the unfertilized egg (reviewed by Dale and Monroy, 1981). In these experiments sperm dilutions that resulted in either $98.7 \%$ monospermy (the maximum degree of fertilization) or lack of fertilization (26\% of total eggs) in adjacent eggs were frequently found to result in polyspermy in the impaled egg when the measured membrane potential was in the $-15 \mathrm{mV}$ range. If the electrode was withdrawn following the recording of such a potential, and then the egg was inseminated, monospermic entries were the rule. A reasonable explanation is that the impalement causes an ionic leakage that both reduces the unfertilized egg membrane potential from about $-80 \mathrm{mV}$ to around $-15 \mathrm{mV}$ and interferes with 
the swift establishment of a rapid block to polyspermy at insemination. Withdrawal of the electrode eliminates the leakage, restoring the membrane potential and polyspermy block capability.

An interpretation of the early events in the sea urchin egg during fertilization is that the triggering of the bioelectrical events responsible for the fast block to polyspermy (Jaffe, 1976) occurs within 2 sec of spermegg contact and binding. Steinhardt et al. (1971) and Jaffe (1976) noted the onset of voltage changes between 3 and $30 \mathrm{sec}$ following insemination. It is of interest that in Table 1 the $-82 \mathrm{mV}$ egg underwent a membrane potential reversal at $240 \mathrm{msec}$ after the onset of the bioelectric response at fertilization, a time consistent with the recent results of Hülser and Schatten (1982), who noted a 50 - to $400-\mathrm{msec}$ rise time in this swift electrical transient. This point might well indicate that -80 $\mathrm{mV}$ eggs (i.e., eggs that are not impaled by a microelectrode) may undergo an even faster response (within a quarter of a second) to sperm adhesion.

During the $12 \mathrm{sec}$ following the onset of the bioelectric responses, the fertilizing sperm is indistinguishable from the other, unsuccessful adherent sperm. Next its tail ceases to beat, the first event visualizable in a light microscope characteristic of sperm incorporation (Epel et al., 1977; Schatten, 1981). A latent period, first proposed by Just in 1919 and studied by Muser (1939) and Allen and Griffin (1958), precedes the appearance of cortical granule secretion. The fertilization envelope does not appear to elevate until about 24 sec after spermegg adhesion; this finding is consistent with capacitance studies performed on a different species at $15^{\circ} \mathrm{C}$ (Jaffe et al., 1978). Recent work by McClay and Fink (1982) characterizing the time course of hyalin appearance on the Tripneustes egg surface, demonstrates two waves of hyalin release, a minor one apparent within $20 \mathrm{sec}$ of insemination and the major release at about a minute. The initial elevation of the fertilization coat, apparent at $35 \mathrm{sec}$ postinsemination, is well preceded by the faster wave of hyalin release. The nature of the triggering of the fertilization potential and the latent period preceding fertilization coat elevation are unknown; it is, however, tempting to speculate that sperm-egg membrane fusion may initiate the fast electrical block to polyspermy (Jaffe, 1976) and that the latent period results from the diffusion of sperm cytoplasmic ions, e.g., $\mathrm{Ca}^{2+}$ (Schackman et al., 1978), in to the egg, which might regulate both sperm-tail motility (Gibbons and Gibbons, 1980 ) and the stimulation of the cortical reaction (Vacquier, 1975). Dale and de Santis (1981) suggest that the fertilization potential is the electrical result of cortical granule discharge; these experiments demonstrate the onset of the electrical events $20.65 \mathrm{sec}$ before the morphological consequence of cortical granule exocytosis, but they do not provide a conclusive answer since the discharge and hydration of the contents of the cortical granules would require a finite time to become visible in the differential interference contrast microscope.

These results indicate that the first sperm initiates the electrical events involved in establishing the fast block to polyspermy probably within 2 sec of adhesion, certainly within $4 \mathrm{sec}$, and well before the start of sperm incorporation and the initiation of the cortical reaction that establishes the slow permanent block to polyspermy (Vacquier et al., 1972). The successful sperm, initially indistinguishable from the other attached ones, can therefore preclude supernumerary entries prior to the onset of incorporation or the cortical reaction.

\begin{abstract}
We thank Dr. Meredith Gould-Somero for the careful review of this manuscript, Dr. Dexter Easton for the generous use of his electrophysiological recording equipment, and Mr. Steve Leukanech for the schematic illustration. G.S. is a recipient of a NIH Research Career Development Award (HD363) from the National Institutes of Health. This research was supported by grants from the Deutsche Forschungsgemeinschaft (Hu 204/7) to D.H. and the National Institutes of Health (HD12913; RR1466) to G.S.
\end{abstract}

\section{REFERENCES}

Allen, R. D., and Griffin, J. L. (1958). The time sequence of early events in the fertilization of sea urchin eggs. I. The latent period and cortical reaction. Exp. Cell Res. 15, 163-173.

Bestor, T. H., and SChatTen, G. (1981). Anti-tubulin immunofluorescence microscopy of microtubules present during the pronuclear movements of sea urchin fertilization. Dev. Biol. 88, 80-91.

Chamrers, E. I., and DE ARMfind, J. (1979). Membrane potential and activation potential of eggs of the sea urchin, Lytechinus variegatus. Exp. Cell Res. 122, 203-218.

Dale, B., De Felice, L. J., and Taglietti, V. (1978). Membrane noise and conductance increase during single spermatozoon-egg interactions. Nature (London) 275, 217-219.

DALE, B., and DE SANTIS, A. (1981). Maturation and fertilization of the sea urchin oocyte: An electrophysiological study. Dev. Biol. 8, 5474-5489.

DALE, B., and MonroY, A. (1981). How is polyspermy prevented? Gamele Res. 4, 151-169.

De FELICE, L. J., and DALE, B. (1979). Voltage response to fertilization and polyspermy in sea urchin eggs and oocytes. Dev. Biol. 72, 327341.

ENDO, Y. (1960). Changes in the cortical layer of sea urchin eggs at fertilization studied with the electron microscope. Exp. Cell Res. 25, 383-397.

Fpfi, D., Cross, N. L., and EpeL, N. (1977). Flagellar motility is not involved in the incorporation of the sperm into the egg at fertilization. Develop., Growth and Differ., 19, 15-21.

GibBons, B. H., and GibBons, I. R. (1980). Calcium-induced quiescence in reactivated sea urchin sperm. $J$. Cell Biol. 84, 13-27.

HAGIWARA, S., and JAFFE, L. (1979). Electrical properties of egg cell membranes. Annu. Rev. Biophys. Bioeng. 8, 385-416.

HARRIS, P., OSBORN, M., and WEBER, K. (1980). Distribution of the tubulin-containing structures in the egg of the sea urchin. $J$. Cell Biol. 84, 668-679.

HÚlSER, D., and SChatTen, G. (1982). Bioelectric responses at fertilization. Gamete Res. 5, 363-377. 
HYLANDER, B. L., and SUmmers, R. G. (1982). An ultrastructural immunocytochemical localization of hyalin in the sea urchin egg. Dev. Biol. 93, 368-380.

JAFFE, L. A. (1976). Fast block to polyspermy in sea urchin eggs is electrically mediated. Nature (London) 261, 68-71.

JAFFE, L. A., HAGIWARA, S., and KADO, R. T. (1978). The time course of cortical vesicle fusion in sea urchin eggs observed as membrane capacitance changes. Dev. Biol. 67, 243-248.

JUST, E. E. (1919). The fertilization reaction in Echinarachnius parma. I. Cortical response of the egg to insemination. Biol. Bull. 16, 1-10.

LONGO, F., and ANDERSON, E. (1968). The fine structure of pronuclear development and fusion in the sea urchin, Arbacia punctulata. $J$. Cell Biol. 39, 339-368.

MCClaY, D. R., and FinK, R. D. (1982). Sea urchin hyalin: Appearance and function in development. Dev. Biol 92, 285-293.

MOSER, F. (1939). Studies on a cortical layer response to stimulating agents in the Arbacia egg. I. Response to insemination. J. Exp. Zool $80,432-445$.

SChaCKMan, R. W., EdDy, E. M., and Shapiro, B. M. (1978). The acrosome reaction of Strongylocentrotus purpuratus sperm. Dev. Biol $65,483-495$.

SCHATTEN, G. (1981). Sperm incorporation, the pronuclear migrations, and their relation to the establishment of the first embryonic axis. Dev. Biol. 86, 426-437.

SCHATten, G. (1982). Motility during fertilization. Int. Rev. Cytol. 79, 59-164.

SchatTen, G., and Mazia, D. (1976). The penetration of the spermatozoon through the sea urchin egg surface at fertilization. Exp. Cell Res. 98, 325-337.

Schatten, H., and SchatTen, G. (1980). Surface activity at the egg plasma membrane during sperm incorporation and its cytochalasin B sensitivity. Dev. Biol. 78, 435-449.

ShapIRo, B. M., and EDDY, E. M. (1980). When sperm meets egg: Biochemical mechanisms of gamete interactions. Int. Rev. Cytol 66, 257-302.

SteINHARDT, R. A., Lundin, L., and MAZIA, D. (1971). Bioelectric responses of the echinoderm egg to fertilization. Proc. Nat. Acad. Sci. USA 68, 2426-2430.

VACQUIER, V. D. (1975). The isolation of the intact cortical granules from sea urchin eggs: Calcium ions trigger granule discharge. Dev. Biol. 43, 62-74.

VACQUIER, V. D., TEgner, M. J., and EPEL, D. (1972). Protease activity establishes the block against polyspermy in sea urchin eggs. Nature (London) 240, 253-353. 